\title{
TRAVESTIS, TRANSEXUAIS E TRANSGÊNEROS NA ESCOLA: UM ESTADO DA ARTE
}

\author{
TRANSVESTITES, TRANSSEXUALS AND TRANSGENDERS AT SCHOOL: a \\ state of the art
} TRAVESTIS, TRANSEXUALES Y PERSONAS TRANSGÉNEROS EN LA ESCUE-
LA: un estado del arte

Neil Franco Doutor em Educação pela Universidade Federal de Uberlândia (UFU). neilfranco010@hotmail.com

Graça Aparecida Cicillini Doutora em Metodologia de Ensino pela Universidade Estadual de Campinas (UNICAMP). gacicillini@gmail.com

\begin{abstract}
RESUMO: Este ensaio apresenta um estado da arte sobre a relação universo trans e Educação, tendo como recorte o período de 2008 a 2014. Identificamos vinte publicações divulgadas na forma de textos em anais de eventos, artigos em periódicos, capítulos de livros, dissertações e teses. O material foi analisado à luz das teorias pós-críticas e sob uma abordagem qualitativa. A emergência de maiores estudos sobre a inserção e permanência de pessoas trans na escola é uma das constatações mais relevantes evidenciadas. Dentro das diversas dimensões que abrangem as discussões sobre gênero e sexualidades dissidentes, travestis, transexuais e transgêneros permanecem historicamente como o segmento social mais exposto a formas de vulnerabilidades e exclusão.
\end{abstract}

PALAVRAS-CHAVE: Universo trans. Educação. Transfobia. Exclusão.

ABSTRACT: This paper presents a state of the art on the relationship between the trans universe and education, from 2008 to 2014. We identified twenty publications disseminated in the form of annals of events, journal articles, book chapters, dissertations and theses. The material was analyzed in the light of post-critical theories and under a qualitative approach. The emergence of larger studies on the inclusion and permanence of trans people in the school is one of the most significant findings highlighted. Within the various dimensions covering discussions about gender and sexuality dissidents, transvestites, transsexuals and transgender historically remain the social segment most exposed to forms of vulnerability and exclusion.

KEYWORDS: Trans universe. Education. Transphobia. Exclusion.

RESUMEN: Este estudio presenta un estado del arte sobre la relación universo trans y Educación, teniendo como recorte el período 2008 a 2014. Se identificaron veinte publicaciones reveladas en forma de textos en los anales de eventos, artículos en periódicos, capítulos de libros, disertaciones y tesis. El material fue analizado a la luz de las teorías post-crítica y bajo una abordaje cualitativa. La emergencia de nuevos estudios sobre la inserción y permanencia de las personas trans en la escuela fue una de las constataciones más relevantes evidenciadas. En las diferentes dimensiones que cubren las discusiones sobre género y sexualidad disidentes, travestis, transexuales y transgéneros permanecen históricamente como el segmento social más expuesto a formas de vulnerabilidad y exclusión.

PALABRAS CLAVE: Universo trans. Educación. Transfobia. Exclusión.

$\overline{\text { Artigo recebido em maio de } 2016}$

Aprovado em julho de 2016 


\title{
1| INTRODUÇÃO
}

Considerando que a escola desde sua criação assumiu o papel social de disciplinamento e ajustamento dos corpos de acordo com as normas vigentes de cada sociedade, Ricardo Henriques et al. (2007) observam que as questões de gênero e sexualidades sempre foram preocupações e pauta presentes no contexto educacional brasileiro, ancoradas nesses princípios de normalização. Esse quadro se modificou a partir do final das décadas de 1970 e 1980 quando o movimento feminista passou a requerer novos olhares sobre as hierarquias de gênero e de sexualidades, enfatizando essas discussões também nos espaços escolares.

Esses efeitos no campo educacional brasileiro foram consolidados, sobretudo no campo legal, mais especificamente na década de 1990, com a criação dos Parâmetros Curriculares Nacionais (PCN) (BRASIL, 2000). Esse documento contemplou a orientação sexual como um tema transversal destacando-o como um de seus cadernos. Contudo, no âmbito da legislação federal, o enfoque nos conteúdos sobre "corpo: matriz da sexualidade", "relações de gênero" e "prevenção às Doenças Sexualmente Transmissíveis/AIDS", pouco avançou além dos limites previstos para o campo da saúde.

\begin{abstract}
Não por acaso, é muito recente a inclusão das questões de gênero, identidade de gênero e orientação sexual na educação brasileira a partir de uma perspectiva de valorização da igualdade de gênero e de promoção de uma cultura de respeito e reconhecimento da diversidade sexual. Uma perspectiva que coloca sob suspeita as concepções curriculares hegemônicas e visa a transformar rotinas escolares, e a problematizar lógicas reprodutoras de desigualdades e opressão. (HENRIQUES et al., 2007, p. 11).
\end{abstract}

Henriques et al. (2007) destacam o surgimento dessas preocupações no contexto escolar na segunda metade dos anos de 1980, principalmente pelo interesse de programas de pósgraduação na constituição de núcleos de estudos e pesquisas sobre gênero e a população de Lésbicas, Gays, Bissexuais e Trans (LGBT), cuja abrangência inicial se restringia ao segmento de lésbicas e gays. A partir da segunda metade dos anos 1990 e até os dias atuais, um número razoável de pesquisas sobre o universo da homossexualidade e o contexto escolar aderiu ao campo investigativo dos intitulados processos de inclusão. A partir dos anos finais da década de 2010 surgiram demandas de pessoas trans junto ao contexto escolar que passaram a identificar a escola como um lugar de pertencimento, apesar dos diversos obstáculos enfrentados por esse segmento social confinado histórica, social e culturalmente ao universo da marginalidade. Nessa perspectiva, propomos, neste momento, realizar um estado da arte sobre estudos que se dedicam à relação universo trans e educação.

Várias formas de identificação de pessoas travestis, transexuais e transgêneros na sigla do movimento LGBT têm sido sugeridas ao longo das teorizações sobre a história dessa categoria no movimento social mais amplo. Nossa opção é a de representar esses sujeitos na sigla apenas com um "T" e em letra com fonte em itálico, que representa a expressão "Trans". Esta opção foi inspirada na expressão "universo trans", descrita por Marcos Benedetti (2005, p. 17), na tentativa de possibilitar a ampliação do leque de definições que abrange as "transformações do gênero" e as "personificações" de gênero polivalente, transformado e modificado.

A aproximação teórica e empírica com essa população tem conduzido à compreensão de que, na maioria das vezes, a tentativa de categorizações identitárias específicas desses sujeitos torna-se um processo equivocado e fadado ao fracasso. Portanto, a expressão trans nos remete de forma mais fluída - a sujeitos que transitam, ultrapassam e/ou permanecem nas fronteiras das sexualidades e, sobretudo, do gênero. 
Dessa forma, compreendemos o gênero como uma construção cultural, negando que ele seja aparentemente fixo como o sexo ou um resultado casual definido por sua estrutura biológica, assim como negamos a possibilidade de compreender o sexo apenas como um dado da natureza ou do destino. Nessa perspectiva, sexo foi desde sempre gênero, matizado pelo discurso. Com isso, abre-se um espaço para pensar o gênero como a interpretação múltipla do sexo, ou ainda, os significados culturais assumidos pelos corpos sexuados, não decorrendo de um sexo propriamente dito, mas considerando que "[...] a distinção sexo/gênero sugere uma descontinuidade radical entre corpos sexuados e gêneros culturalmente construídos" (BUTLER, 2003, p. 24).

Partilhando de dimensões intrínsecas ao gênero, a sexualidade está inserida na condição humana de forma ontológica; ou seja, é uma manifestação inerente a todos e a cada ser humano em particular, é uma das dimensões privilegiadas de sua manifestação subjetiva, histórica e social (NUNES; SILVA, 2000). A sexualidade também pertencente ao campo político, pois é "[...] 'aprendida', ou melhor, é construída, ao longo de toda a vida, de muitos modos, por todos os sujeitos" (LOURO, 1999, p. 11).

Considerando essa postura conceitual, nosso caminho teórico-metodológico foi trilhado e ancorado nas teorias pós-críticas do conhecimento. Para Tomaz Tadeu da Silva (2007), esse campo sucedeu às teorias críticas cujo foco consiste na influência dos processos de dominação de classe subsidiados pela exploração econômica que se efetivaram como poderosas e insubstituíveis ferramentas de análise das sociedades de classes realizadas pela teoria marxista. Partilhando fundamentos epistemológicos elaborados pelas teorias críticas, as teorias pós-críticas assentiram ao campo de análise social outros processos de dominação tais como raça, etnia, gênero e sexualidades, oportunizando outras interpretações para os conceitos de alienação, emancipação, libertação e autonomia. Ampliam-se, como isso, as possibilidades de compreensão dos processos estabelecidos a partir das relações de poder e dominação que nos têm constituído historicamente.

Em consonância com essa vertente, Marlucy Paraíso (2012) ressaltou o procedimento de construção metodológica de pesquisa pós-crítica como a busca de diferentes inspirações e articulações para a reconstrução dos saberes sobre Educação e currículos. Dessa forma: "Ocupamo-nos do já conhecido para suspender significados, interrogar os textos, encontrar outros caminhos, rever e problematizar os saberes produzidos e os percursos trilhados por outros" (PARAÍSO, 2012, p. 25).

Em razão disso, o termo metodologia refere-se a certa maneira de elaborar perguntas, interrogações, questões e problemas de investigação que se articulam a um conjunto de "procedimentos de coleta de informações" e à vertente teórica escolhida, contudo, assumindo um caráter mais livre comparado ao sentido moderno do conceito de "método". Para os/as teóricos/as pós-críticos/as o método visa à produção de informações e, consequentemente, "estratégias de descrição e análise" (MEYER; PARAÍSO, 2012, p. 16).

Considerando essas argumentações teórico-metodológicas, investimos na relevância de ressaltar descritiva e analiticamente como a temática trans se faz presente na construção do conhecimento, sendo, a nosso ver e pautado em Paraíso (2012), uma possibilidade de reconstrução de saberes que restritamente adentram o campo educacional. Com isso, optamos como recorte temporal, por estudar o período de 2008 a 2014. Tal recorte se justifica pelo período que essa temática passou a integrar, com mais intensidade, as dimensões acadêmicas brasileiras como campo de interesse investigativo.

Segundo Norma Ferreira (2002), as pesquisas que se propõem a realização de um "estado da arte" são definidas como de caráter bibliográfico e assumem o desafio de mapear e discutir produções acadêmicas em determinado campo do conhecimento com o intuito de responder que aspectos e dimensões, épocas e lugares, formas e condições, se constituem esses campos, podendo 
realizar essa construção através da análise de variadas fontes, tais como: dissertações, teses, publicações em periódicos e comunicações em anais de congressos e de seminários.

Também são reconhecidas por realizarem uma metodologia de caráter inventariante e descritivo da produção acadêmica e científica sobre o tema que busca investigar, à luz de categorias e facetas que se caracterizam enquanto tais em cada trabalho e no conjunto deles, sob os quais o fenômeno passa a ser analisado. (FERREIRA, 2002, p. 257).

Sendo nosso fenômeno analisado a relação universo trans e educação, em nossas buscas identificamos vinte publicações entre 2008 e 2014 divulgadas em fontes variadas.

Quadro 1 - Descrição publicações Universo trans e Educação

\begin{tabular}{|c|c|c|}
\hline Grupo & Tipo de Publicação & Publicações Encontradas \\
\hline \multirow{3}{*}{01} & Texto publicado Anais de Evento & 03 \\
\cline { 2 - 3 } & Artigo revista eletrônica & 02 \\
\cline { 2 - 3 } & Capítulo de livro & 05 \\
\hline \multirow{2}{*}{02} & Dissertação & 06 \\
\cline { 2 - 3 } & Tese & 04 \\
\hline \multicolumn{2}{|c}{ Total } \\
\hline
\end{tabular}

Fonte: Elaborado pelos autores.

Como descrito no quadro 01, as vinte publicações encontradas sobre a relação universo trans e Educação foram divididas em dois grupos, ambos compostos por dez publicações. No grupo 01, identificamos três textos publicados em Anais de Eventos, dois artigos disponíveis em revistas eletrônicas e cinco capítulos de livro. Seis dissertações e quatro teses agregam o grupo 02.

A busca por esse material teve início em 2006 quando iniciávamos as investigações sobre a relação educação e população LGBT no contexto mais amplo. Desde esse período, já nos parecia claro que pessoas trans consistiam daquelas com menor acesso e foco de discussão no campo educacional. Contudo, essas buscas foram mais eminentes entre 2008 e 2014.

De modo geral, chegamos à maioria do material levantado através de pesquisa em fontes terciárias, ou seja, referências apresentadas em artigos de revistas e livros, dissertações e teses que tivemos acesso inicialmente. A participação e filiação a grupos de trabalho sobre gênero, sexualidade e educação foi outro espaço de busca relevante, destacando, sobretudo, o Grupo de Trabalho em Gênero, Sexualidade e Educação (GT-23) da Associação Nacional de Pós-Graduação e Pesquisa em Educação-ANPEd.

O vínculo ao movimento organizado de pessoas trans, foi outro espaço de identificação do material, uma vez que, participando de alguns eventos como o Encontro Nacional de Travestis e Transexuais na Luta contra a Aids (ENTLAIDS), tivemos acesso a pesquisadores/as que se dedicavam a esse campo de investigação. Redes sociais, como Facebook, também nos permitiram contato com pessoas e grupos que nos conduziram também a parte desse material, nos deixando atualizados sobre pesquisas em andamento e que se concluíam ao longo do trajeto de buscas.

Neste sentido, como descrito por Dagmar Meyer e Marlucy Paraíso (2012), o caráter mais livre comparado ao sentido moderno do conceito de "método" que define as metodologias de investigação pautadas nas teorias pós-críticas foi para nós o caminho mais favorável, uma vez que nossas procuras nos bancos de dados mais destacados nos meios acadêmicos (como o portal do Scielo, por exemplo) não foram muito frutíferas. As poucas publicações encontradas foram realizadas ou 
no portal do Google Acadêmico e, também, no Google convencional que ao lançarmos palavras relacionadas como travesti-transexuais-educação, pessoas trans-educação, travestis-contexto escolar, etc. chegamos a trabalhos oriundos de comunicações orais apresentadas em eventos e artigos publicados em revistas eletrônicas que, nos conduziram, em alguns momentos, ao portal específico do Scielo.

No trajeto investigativo também encontramos textos e artigos que se originaram das investigações de mestrado e doutorado aqui descritas, com isso, estas publicações não integraram nosso levantamento. Privilegiamos esses estudos em sua íntegra, sob a forma de dissertações e/ ou teses, acreditando na relevância de construir um documento de acesso aos trabalhos originais para outros/as pesquisadores/as que venham se interessar por esse campo de conhecimento dificuldade por nós vivenciada em nosso caminho investigativo.

Inspirados/as numa abordagem qualitativa, a partir do material elencado, identificamos as vertentes investigativas predominantes nessas publicações, assim como os aspectos metodológicos, campos teóricos e resultados mais representativos. Estabelecer análises destacando os aspectos concordantes e discordantes, entre esses estudos, foi outra tentativa; no entanto, em razão do espaço disponibilizado para sua realização e o número de publicações, possivelmente essa tarefa se cumpra de forma parcial, ficando o convite/provocação para outros/as pesquisadores/as a contribuírem e ampliarem este estudo.

No decorrer deste trabalho serão primeiramente descritas e problematizadas as publicações do grupo 01 - textos, artigos e capítulos de livros. Na sequência nos deteremos ao grupo 02 - as dissertações e teses. Em momento algum essa opção de apresentação e contextualização dos trabalhos teve a intenção de atribuir critérios de relevância às diferentes formas de publicação. Apenas consistiu da melhor estrutura organizacional das problematizações por nós encontrada, ou, como descrito por Meyer e Paraíso (2012), nossa forma "livre" de construir estratégias descritivas e analíticas fundamentado nas teorias pós-críticas.

\section{2 | UNIVERSO TRANS E EDUCAÇÃO: TEXTOS, ARTIGOS E CAPÍTULOS}

O quadro 02, abaixo, apresenta de forma esquemática as publicações que integram o grupo 01 de nossas análises destacando o título da obra, autorla(s), o tipo de publicação e o ano. Com o intuito de dinamizar a descrição no quadro, utilizamos para informar o tipo de publicação do grupo 01 o seguinte critério: texto - texto publicado em anais de evento; artigo - artigo disponibilizado em revista eletrônica; capítulo - capítulo de livro.

Quadro 2 - Grupo 1: Universo trans e Educação: textos, artigos e capítulos.

\begin{tabular}{|l|c|}
\hline \multicolumn{1}{|c|}{ Titulo publicação/ autor/a(s)/ tipo de publicação } & Ano \\
\hline Na escola se aprende que a diferença faz a diferença/ Berenice Bento/capítulo & 2008 \\
\hline $\begin{array}{l}\text { Um nome próprio: transexuais e travestis nas escolas brasileiras/ Maria Rita A. César/ } \\
\text { texto }\end{array}$ & 2008 \\
\hline $\begin{array}{l}\text { Cenas de exclusões anunciadas: travestis, transexuais, transgêneros e a escola brasile- } \\
\text { ira /William Peres/capítulo }\end{array}$ & 2009 \\
\hline $\begin{array}{l}\text { Espaço escolar e diversidade sexual: um desafio às políticas educacionais no brasil/lvan } \\
\text { J. Junckes e Joseli M.Silva/artigo }\end{array}$ & 2009 \\
\hline $\begin{array}{l}\text { Educação e homofobia: o reconhecimento da diversidade sexual para além do multicul- } \\
\text { turalismo/ Rogério Diniz Junqueira/capítulo }\end{array}$ & $2009 a$ \\
\hline
\end{tabular}




\begin{tabular}{|l|c|}
\hline Homofobia nas escolas: um problema de todos/ Rogério Diniz Junqueira/capítulo & $2009 \mathrm{~b}$ \\
\hline $\begin{array}{l}\text { Políticas de educação para a diversidade sexual: escola com lugar de direitos/Rogério } \\
\text { Diniz Junqueira/capítulo }\end{array}$ & $2009 \mathrm{c}$ \\
\hline $\begin{array}{l}\text { Banheiros, travestis, relações de gênero e diferenças no cotidiano da escola/Elizabete } \\
\text { F. Cruz/artigo }\end{array}$ & 2011 \\
\hline $\begin{array}{l}\text { Gênero, educação \& diversidade: sociabilidade das travestis nos ambientes educacio- } \\
\text { nais na cidade de Maceió/AL/Manuella P. H. Cavalcanti/texto }\end{array}$ & 2011 \\
\hline $\begin{array}{l}\text { Cenas Escolares Vivenciadas por Travestis: desafios à formação docente/Sandro P. } \\
\text { Santos e Fernanda F. S. Rodrigues/texto }\end{array}$ & 2014 \\
\hline
\end{tabular}

Fonte: Elaborado pelos autores.

De acordo com nossas investigações, Berenice Bento (2008) possivelmente tenha sido uma das primeiras a realizar investigações sobre universo trans e educação no contexto brasileiro. A autora problematizou sobre os critérios de normalidade e anormalidade instituídos pelas instituições sociais ao lidarem com as demandas de pessoas "que vivem o gênero para além da diferença sexual". No que concerne à escola, esses critérios foram contextualizados pela análise dos relatos de pessoas transexuais relacionados a referenciais teóricos e às implicações descritas na quarta edição do Manual de Diagnóstico e Estatística de Doenças Mentais - DSMIV (AMERICAN PSYCHIATRIC ASSOCIATION, 1995). A partir dessas fontes de análise é possível confirmar, como descreve o subtítulo dessa parte da obra, que "na escola se aprende que a diferença faz a diferença". No sentido mais amplo a autora conclui que "[...] há um projeto social, uma engenharia de produção de corpos normais que extrapola os muros da escola, mas que encontrará neste espaço um terreno fértil de disseminação" (BENTO, 2008, p. 131). Neste projeto social, o artifício de exclusão social de pessoas trans acaba sendo anunciado e definido convenientemente como evasão escolar.

Maria Rita César (2009) se utiliza da teoria sobre a "engenharia de produção de corpos normais" de Bento (2008) para nortear as discussões sobre os obstáculos enfrentados na utilização do nome social por pessoas trans como um demarcador da recusa desses sujeitos pelas instituições escolares. Isso também confirma o artifício da exclusão invisibilizado pelo discurso da evasão escolar.

O reconhecimento do nome social representa a forma principal de produção da subjetividade na experiência contemporânea da transexualidade. Os artefatos escolares como as listas de chamada, os exames e mesmo uma simples abordagem em sala de aula fazem uso dos nomes e estes nomes estão demarcados no interior das regras normativas do sistema corpo-sexo-gênero. (CÉSAR, 2009, p. 12).

De forma similar, essa discussão foi também reiterada por William Peres (2009) ao argumentar sobre as dificuldades da escola em lidar com as questões referentes às identidades de gênero e sexual, especialmente quando os sujeitos em foco são pessoas trans. Ou seja, isso acaba por resultar em "modelos sociais de exclusão" por meio de ações de violência e/ou, concomitantemente, descaso dessas ações por parte da instituição escolar. Neste sentido, o autor esclarece que: "Quanto mais enrijecidos e cristalizados forem os valores norteadores dos programas de ensino, quanto mais reguladoras forem as atividades formadoras, mais reificação de desigualdades, discriminação e exclusão social será estabelecida" (PERES, 2009, p. 251).

As argumentações de Peres (2009) corroboram com os resultados da investigação de Ivan Junckes e Joseli Silva (2009, p. 164) ao concluírem que: 


\begin{abstract}
O resgate das experiências das travestis no espaço escolar evidencia que a escola tende a reproduzir o preconceito e a discriminação presentes na sociedade brasileira em relação às sexualidades consideradas fora das normas hegemônicas. Elas revelam outra versão do significado construído sobre o espaço escolar, tradicionalmente considerado um local protegido, onde são cultivadas as regras do respeito, da cidadania, da igualdade e do acesso universal ao conhecimento.
\end{abstract}

Ancorado teoricamente na "abordagem das pluralidades" como proposta da Nova Geografia Cultural e em estudiosos/as vinculados/as às teorias pós-críticas, o estudo teve como objetivo refletir sobre as experiências de inclusão/exclusão de travestis na escola. O material empírico foi construído a partir da realização de entrevistas a treze travestis da cidade de Ponta Grossa no ano de 2007. As políticas governamentais de combate à discriminação sexual e promoção de direitos humanos compõem também o campo analítico do estudo, conduzindo à seguinte conclusão:

Acredita-se que os esforços políticos realizados pelo governo brasileiro, em conjunto com a sociedade civil, através da implementação de importantes projetos, apenas tangenciam transformações no cotidiano escolar. Há resistências a serem vencidas, desde a incorporação dos temas transversais (raça, etnia, gênero e sexualidade) nas disciplinas convencionais, na atualização da linguagem visual e escrita dos livros didáticos, até a formação de professores capazes de lidar com conflitos em torno da deflagração de atos discriminatórios contra pessoas que fogem da ordem heterossexual. (JUNCKES; SILVA, 2009, p. 164).

As argumentações desses estudos foram explicitadas por Rogério Junqueira (2009a, 2009b, 2009c) que especificou em suas teorizações conceitos como "sinergia de vulnerabilidades" e "pedagogia do insulto" como norteadores das relações estabelecidas por pessoas LGBT no contexto escolar.

Nesses textos, o autor destaca a forma como esses processos de vulnerabilidade afetam de maneira mais significativa o segmento trans por se consistir de um grupo ainda menos mobilizado politicamente em certas demandas sociais (a escolar, mais especificamente), principalmente pelos contextos de humilhação, segregação, guetização e opressão pelas quais são expostas, o que lhes vetam o acesso a direitos universais do ser humano, como a educação. Ainda assim, a escola representa para esse autor o espaço no qual mudanças e novas possibilidades de reconstrução dos valores de humanidade, cidadania e democracia possam ser estabelecidas.

Neste processo, a formação inicial e continuada de docentes, gestores/as, etc. consiste em um dos caminhos que necessitam maiores investimentos para que o respeito às diferenças seja uma temática constantemente em pauta na escola. Junckes e Silva (2009) destacam essa perspectiva ancorados/as na necessidade de cumprimento das políticas públicas de inclusão.

Elizabete Cruz (2011) propõe reflexões a partir de vivências do cotidiano. Ela problematiza identidades de gênero interpretadas como marginais e seus processos de significação no contexto escolar inspirada em reflexões elaboradas a partir de três momentos de sua atuação profissional: a experiência como professora de um módulo enfocando o cotidiano escolar em um curso de especialização em gestão educacional, direcionado a gestores/as de escolas da rede estadual de São Paulo nos anos de 2005 e 2006; as inquietações despertadas pelo filme Transamérica; e eventos ocorridos na organização de um encontro de jovens que viviam com Aids.

A questão propulsora das discussões é a polêmica de utilização do banheiro por pessoas travestis; foco que estimula inquietantes indagações que se mesclam, como descrito pela a autora, em um "caleidoscópio de pistas" em que emerge de forma representativa "a anormalidade produzida nos fios do fundacionalismo biológico, binarismo e heteronormatividade". Esses incômodos são pensados, sobretudo, na dinâmica do cotidiano escolar ancorados na teoria foucaultiana e dos estudos de gênero - de origem feminista e pós-estruturalista. 
No cotidiano, tematizamos seu banheiro [das travestis], mas não sua expulsão velada e os resultados deste processo em sua vida, seja em termo analfabetismo, dificuldades com a escolaridade ou ainda em relação ao que poderão dizer de si mesmas. Por que a o banheiro a ser utilizado por uma travesti pode gerar mais polêmica do que o fato de que as escolas podem estar contribuindo para a exclusão (explicita ou implícita) de travestis? (CRUZ, 2011, p. 13).

Mediante essa argumentação, a autora ressalta que a questão sobre qual banheiro a travesti deve utilizar na escola, ou demais espaços públicos, consiste apenas a ponta do iceberg de uma imensidão de processos de exclusão e vulnerabilidade vivenciados por pessoas trans em nossa sociedade.

Subsidiada pelo conceito de "pedagogia do insulto" (JUNQUEIRA, 2009b), Manuella Cavalcanti (2011) contextualiza histórias escolares de travestis da cidade de Maceió. Ressaltou que em razão das marcas da transgressão do gênero demarcadas em seus corpos, as travestis agregam o segmento mais exposto a formas variadas de violência no contexto escolar.

Se homossexuais masculinos e/ou femininos, podem manter sua identidade sexual em segredo por medo do preconceito, discriminação, as travestis trazem no corpo, (e não só nele), a desconstrução e construção da identificação de gênero, sendo, então, expostas a todo e qualquer tipo de preconceito. (CAVALCANTI, 2011, p. 9).

Por outro lado, Cavalcanti (2011) também identificou contextos nos quais se instauravam indícios de uma "pedagogia do respeito", em que os efeitos nocivos da normalização do gênero afetavam de forma mais branda as relações escolares de algumas das travestis investigadas. Isso mobilizou parte desses sujeitos a concluírem seus estudos e almejarem outros espaços de atuação profissional diferentes do universo da prostituição.

Essa "desconstrução e construção da identificação de gênero" (CAVALCANTI, 2011, p. 9) elaborada pelas travestis na escola foi também o foco de inquietação de Sandro Santos e Fernanda Rodrigues (2014). A partir de cenas escolares vivenciadas por quatro travestis de uma cidade de Minas Gerais, estabeleceram um diálogo entre a formação docente e as questões de construção dos gêneros dissidentes no espaço escolar. De forma sucinta, destacam a metodologia e as conclusões apresentadas pelo estudo da seguinte forma:

\footnotetext{
Utilizamos a perspectiva metodológica da pesquisa qualitativa, realizando entrevistas semiestruturadas. As informações foram analisadas fundamentando-se na técnica de Análise de Conteúdo. As análises evidenciam que as relações entre a escola e as experiências da travestilidade estabelecem-se no campo do estranhamento e da tensão, ocasionando a rejeição e a exclusão desses sujeitos, por meio das violências e práticas pedagógicas, associadas às regulações e normatizações de suas condutas. (SANTOS; RODRIGUES, 2014, p. 1).
}

De acordo com esses estudos podemos situar a exclusão, a vulnerabilidade, o preconceito, a discriminação e o desrespeito aos direitos da pessoa humana como as dimensões que, com raras exceções, determinam a presença de pessoas trans na escola mesmo antecedendo seu processo de transformação, aspecto relatado por vários dos sujeitos que integraram esses estudos narrando suas vivências no contexto escolar. Esses aspectos se ampliam ao nos determos nas pesquisas acadêmicas concluídas enfocando a temática do universo trans e educação. 


\section{3 | UNIVERSO TRANS E EDUCAÇÃO: DISSERTAÇÕES E TESES}

Integrando o grupo 02 de nossas análises, apresentadas no quadro 03, encontramos dez investigações enfocando universo trans e Educação entre o período de 2009 a 2014, sendo seis que investigaram discentes trans e cinco que realizaram pesquisas com docentes trans. As análises deste grupo se deterão primeiramente às vivências relacionadas ao contexto discente e, em seguida, destacaremos os contextos docentes. Assim como no quadro 02, destacamos os títulos das obras, autor/a(s), tipo de publicação e o ano de sua conclusão.

Quadro 3 - Grupo 2: Universo trans e Educação: dissertações e teses.

\begin{tabular}{|l|c|}
\hline \multicolumn{1}{|c|}{ Titulo publicação/ autor/a(s)/ tipo de publicação } & Ano \\
\hline $\begin{array}{l}\text { Os "monstros" e a escola: identidade e escolaridade de sujeitos travestis/Alessandra M. } \\
\text { Bohm/dissertação }\end{array}$ & 2009 \\
\hline $\begin{array}{l}\text { Montagens e desmontagens: vergonha, desejo e estigma na construção das travestili- } \\
\text { dades na adolescência/Tiago Duque/dissertação }\end{array}$ & 2009 \\
\hline $\begin{array}{l}\text { Cartografias da transexualidade: a experiência escolar e outras tramas/Dayana B. C. } \\
\text { Santos/dissertação }\end{array}$ & 2010 \\
\hline Travestilidades e escola nas narrativas de alunas travestis/Adriana Sales/dissertação & 2012 \\
\hline $\begin{array}{l}\text { Travestis na escola: assujeitamento e resistência à ordem normativa/Luma N. Andrade/ } \\
\text { tese }\end{array}$ & 2012 \\
\hline $\begin{array}{l}\text { A diversidade entra na escola: histórias de professores e professoras que transitam } \\
\text { pelas fronteiras da sexualidade e do gênero/Neil Franco/dissertação }\end{array}$ & 2009 \\
\hline $\begin{array}{l}\text { Gênero e sexualidade: um encontro político com as epistemologias de vida e os movi- } \\
\text { mentos curriculares/ Márcio R. V. Caetano/tese }\end{array}$ & 2011 \\
\hline $\begin{array}{l}\text { A emergência de professoras travestis e transexuais na escola: heteronormatividade e } \\
\text { direitos nas figurações sociais contemporâneas/Marco Antônio Torres/tese }\end{array}$ & 2012 \\
\hline $\begin{array}{l}\text { A pedagogia do salto alto: histórias de professoras transexuais e travestis na educação } \\
\text { brasileira/Marina reidel/dissertação }\end{array}$ & 2013 \\
\hline $\begin{array}{l}\text { Professoras trans brasileiras: ressignificações de gênero e de sexualidades no contex- } \\
\text { to escolar/Neil Franco/tese }\end{array}$ & 2014 \\
\hline
\end{tabular}

Fonte: Elaborado pelos autores.

Alessandra Bohm (2009) analisou depoimentos de discentes travestis com relação à Educação Formal; problematizou questões como inclusão e educação com o intuito de levantar critérios que estabelecessem a convivência delas na escola. Sua metodologia abrangeu duas etapas: na primeira realizou uma análise quantitativa a partir de informações obtidas por meio de entrevistas (semiestruturadas) com vinte travestis da cidade de Porto Alegre-RS e região; em seguida, a autora dedicou-se a uma análise qualitativa, entrevistando cinco pessoas envolvidas em contextos educacionais em que travestis se inseriam ou foram inseridas: uma professora de escola pública estadual de Ensino Médio, conhecida pela diversidade de sua clientela de ensino; uma travesti que concluiu o Ensino Médio na mesma escola; uma transexual que é professora de séries iniciais em uma escola pública municipal do RS; uma entrevista com a travesti coordenadora e fundadora do grupo Igualdade; e, para finalizar, uma entrevista informal com a professora que ministrou um projeto de alfabetização de travestis (BOHM, 2009).

A articulação com a perspectiva pós-estruturalista foi a opção teórica adotada; com isso, as análises se encontram imersas nos princípios dos Estudos Culturais, Estudos Feministas e de Gênero, Estudos Gays e Lésbicas e teoria queer. Como resultados, a pesquisa indicou a travestilidade 
como uma manifestação do humano que perturba a organização escolar e a heteronormatividade na qual se encontra imersa. Constatou que eram restritos os casos de ingresso, resistência e permanência de travestis na escola em razão do bullying que vivenciam cotidianamente mesmo pelo corpo docente e gestores/as que lhes recusam a utilização do nome social e de roupas e adereços femininos, como exemplo. "A escola, tal qual como se organiza e se estrutura hoje, não é para as travestis ou para qualquer outro "monstro" que fuja às normas socialmente estabelecidas" (BOHM, 2009, p. 83).

Ao contextualizar as relações estabelecidas entre travestilidade, juventude, prostituição, escola e família, Thiago Duque (2009) questionou o motivo pelo qual dificilmente se identifica sobreposição dos referenciais de feminilidade das travestis na relação com a família e a escola, comparado à forma como esses referenciais são construídos no universo da prostituição. A conclusão do autor remeteu à citação anterior de Bohm (2009) no sentido de explicitar que a imposição de se aderir a uma relação causal e linear produzida pela tríade sexo-gênero-sexualidade é inerente ao universo familiar e escolar. Isto é, mesmo dentro de um processo de aceitação e tolerância de travestis no contexto escolar - como descrito pelos sujeitos de sua pesquisa -, ainda prevalecem processos de recusa de pessoas que transgridam as normas de gênero e das sexualidades.

A partir do que foi informado pelas pessoas trans investigadas, de acordo com Duque (2009), a 'pista', a 'rua', o local de prostituição consistem em um espaço de livre reconhecimento de seus gêneros, mesmo que o mercado do sexo não seja interpretado como o melhor lugar para a convivência social. Ele investigou os processos de construção dos corpos de travestis adolescentes da cidade de Campinas-SP, buscando compreender suas estratégias de construção da feminilidade em meio às reações de repressão e controle social por contrariarem os princípios da heteronormatividade. Como referencial teórico, ancorou-se nos princípios da teoria queer. Metodologicamente, a pesquisa etnográfica foi a opção que utilizou realizando observação de campo e entrevista com seis jovens como procedimento para a construção e análise dos dados. As relações estabelecidas por esses sujeitos com o contexto escolar não foi o foco da pesquisa, contudo, o autor não descartou a discussão desse espaço social como integrante do universo de constituição social destes sujeitos.

Estabelecendo aproximações com o estudo de Cavalcanti (2011) sobre a o possível estabelecimento de indícios de uma "pedagogia do respeito", apesar de a escola não consistir espaço primeiro de reconhecimento da feminilidade de pessoas trans, principalmente em razão da heteronormatividade, Duque (2009) observou que suas entrevistadas relataram relações amistosas e um tanto confortáveis no contexto escolar nas quais eram respeitadas na maioria do tempo. Isso ocorreu, sobretudo, pelo reconhecimento de seus nomes sociais tanto por parte do corpo discente quanto docente. Nos casos de abandono da escola, a exclusão não foi o motivador principal, mas, escolhas pessoais e profissionais feitas pelo sujeito em que os processos de formalização do contexto escolar tornavam-se um complicador. Esse aspecto foi, de certa forma, verificado também por Dayana Santos (2010) ao investigar transexuais do Paraná.

Subsidiada por autores/as que se vinculam às teorias contemporâneas do conhecimento, tais como Michel Foucault, Gilles Deleuze, Judith Butler, e outros/as, Santos (2010) analisou o processo de escolarização por meio de narrativas de travestis e transexuais. A pesquisa teve como foco a discussão de formas de sexualização e generificação sociais pautadas na efetivação da heteronormatividade, os gêneros como expressões performáticas e a transexualidade e seus processos de patologização.

O material empírico foi elaborado a partir das narrativas de seis mulheres transexuais e um homem transexual de Curitiba obtidas por meio de entrevista de caráter semiestruturado. Outro método utilizado para a construção dos dados foi por meio de um grupo de discussão com lideranças do Movimento Social de Travestis e Transexuais da Região Sul do Brasil. Analisado à luz do referencial 
teórico proposto, esse material empírico deu origem ao mapeamento dos sentidos produzidos pelos sujeitos, ou, na perspectiva deleuzeana, um "mapa cartográfico".

Como alguns dos resultados mais interessantes, tanto nas entrevistas quanto no material produzido a partir do grupo de discussão, a exclusão era um fator recorrente na escola vivenciado pelos sujeitos, contudo, a autora ressaltou que os dados tornaram-se insuficientes para afirmar uma relação causal entre exclusão e abandono da escola. Em parte das narrativas o abandono da escola vinculava-se à questão de recursos financeiros e/ou questões familiares, o que alterou as trajetórias de vida desses sujeitos. Em outros casos, a normalização dos corpos e das vivências como princípios inerentes ao contexto escolar fazia que esse espaço não se constituísse de uma prioridade para os sujeitos trans investigados.

Adriana Sales (2012) investigou a inserção e permanência de jovens travestis nas escolas públicas de Cuiabá-MT. A partir das narrativas de quatro travestis obtidas por meio de entrevista semiestruturada, que foram analisadas à luz das teorias contemporâneas do conhecimento, a escola foi compreendida como um espaço de correção e vigilância dos princípios heteronormativos definidores socialmente do masculino e do feminino.

A travestilidade foi interpretada como "não coerente no sentido comportamental", portanto, patológica, desviante e passível de hostilidade. Ao mesmo tempo, a autora verificou um processo de resistência por parte das discentes no sentido de desencadear ressignificações da transfobia: "[...] essas alunas não querem ausentar-se e, mais que isso, reconhecem nesses espaços e etapas de vida importante e significativo momento para serem reconhecidas, contempladas como humanas e como mais uma variante das possibilidades de existir" (SALES, 2012, p. 106). Essa constatação distancia-se das percepções apresentadas pelos sujeitos investigados por Duque (2009) e Santos (2010), para os/as quais há pouca representatividade da escola em suas vidas foi atribuída.

Por outro lado, as conclusões de Sales (2012) corroboram com as observações realizadas por Luma Andrade (2012) ao delinear novas formas de visualização de travestis pelo imaginário social. Isto é, identificá-las necessariamente como sujeitos rejeitados pela família, escola ou sociedade - sujeitas unicamente à prostituição -, não consiste de seu único destino. Fato evidenciado pelo enfrentamento e luta pelo reconhecimento de suas identidades sociais em outras dimensões, das quais a escola foi uma delas.

Estabelecendo diálogos com teóricos/as que integram as teorias contemporâneas do conhecimento, Andrade (2012) investigou travestis cearenses no espaço escolar enfocando processos de socialização, resistências e assujeitamentos à ordem normativa. Construiu sua problematização a partir das narrativas de travestis estudantes e que já passaram pela escola e pelas percepções de alunos/as, professores/as e gestores/as que conviveram com esses sujeitos no cotidiano escolar.

Como metodologia utilizou a análise de fontes bibliográficas, documentais, entrevistas e questionários dimensionados sob uma abordagem etnográfica. Para a autora, "A presença das travestis nas escolas se apresenta como dispositivo relevante para a formação da comunidade escolar na convivência com as singularidades delas, mesmo em meio a profundos conflitos" (ANDRADE, 2012, p. 248).

Uma singularidade do trabalho de Andrade (2012) foi que ao construir uma etnografia de travestis na escola, a autora desenvolveu um ir e vir entre sujeitos e pesquisadora em razão da construção de seu corpo trans ter sido também influenciada pelas nuances do contexto escolar, o que resultou na sua constituição profissional como docente. Dessa forma, o texto nos permitiu conhecer parte significativa de suas vivências escolares - sempre contextualizadas e comparadas às vivências dos sujeitos investigados -, assim como compreender seu trajeto de construção docente. Portanto, sua tese se encontra na fronteira entre as pesquisas que enfocaram alunas/os trans na escola e aquelas que se detêm às professoras trans. 
Com o objetivo de compreender e problematizar aspectos da constituição identitária de professores/as que transitam pelas fronteiras das sexualidades e do gênero, Neil Franco (2009) investigou o que docentes lésbicas, gays e travestis da cidade de Uberlândia-MG contavam de suas histórias de vida e o lugar ocupado pela profissão docente nesse processo. Considerou como suas identidades sexuais e de gênero eram evidenciadas e interpretadas pelos diversos sujeitos que constituem a escola, em especial, o corpo docente.

Foram entrevistados três professores gays, duas professoras travestis e uma professora lésbica. Também foi aplicado um questionário aos docentes e gestores/as em três escolas da rede municipal nas quais três dos sujeitos trabalhavam no ano de 2007. O material empírico e documental foi analisado e contextualizado à luz das teorias pós-críticas.

Um dos principais aspectos evidenciados foi que o/a professor/a gay, travesti e lésbica ao
exercer a profissão docente não se desvincula das marcas da sexualidade e do gênero
inscritas em seu corpo, mesmo que não as anuncie, deixando flagrar notadamente a dife-
rença provocando impactos tanto em alunos/as, docentes e em outros sujeitos envolvidos
no processo educativo, confirmando a estreita relação da escola com os princípios religio-
sos e morais que desde sua criação permanecem determinando as diretrizes da profissão
docente e atribuindo aos profissionais dessa área (sob a concepção de sujeito estável, fixo
e hegemônico) o legado de "modelo a ser seguido" e "exemplo". (FRANCO, 2009, p. 213).

Propondo diálogos com os estudos feministas e culturais, Márcio Caetano (2011, p. 24) problematizou os discursos referentes aos gêneros e as sexualidades "[...] que produziram corporalidades e interpelaram os movimentos curriculares de professoras e professores que transitam na ilegibilidade ou na incoerência heteronormativa." Apresentou como metodologia a construção de "(re)fazeres biográficos" que, ancorados em configurações sociais pós-modernas, sugerem a ampliação das experiências pessoais, profissionais e a percepção da corporeidade. Essas contextualizações tiveram o intuito de interrogar o que o autor identificou como "projeção de gênero" que pode influenciar na forma como desenvolvemos processos de percepção, articulação e narração diante das redes de sociabilidades a que pertencemos. Cinco docentes da região sul do país forneceram narrativas para essa investigação, das quais duas eram professoras transexuais. Um sexto sujeito entrou em cena: o próprio pesquisador.

[...] percebo que a 'masculinidade' e 'feminilidade' têm sido ampliadas e o corpo anatômico é apenas um suporte de invenções estimuladas pela sexualidade. Os novos arranjos proporcionados pelas sexualidades e pelos gêneros improvisam outros arranjos identitários interagindo com os movimentos curriculares e produzindo tensões cotidianas na escola. (CAETANO, 2011, p. 11).

Marco Torres (2012) pesquisou a emergência de professoras trans correlacionada à ascensão das demandas pelos direitos LGBT na contemporaneidade. Buscou conhecer as impressões das professoras sobre a escola e suas lutas contra a discriminação, motivado pela argumentação de que ocupando a posição de docentes conseguiriam identificar mudanças em andamento na escola bem como em dimensões sociais mais amplas.

A metodologia utilizada pautou-se na análise de documentos referentes às políticas de direitos humanos e entrevistas realizadas com sete professoras trans brasileiras, interpretadas à luz das relações entre "estabelecidos" e "outsiders" teorizadas por Norbert Elias e, ainda, em alguns conceitos elaborados por Judith Butler. "As professoras trans têm conseguido firmar-se por diversos modos, entre os quais consideramos as medidas judiciais e alianças com movimentos sociais e organizações LGBT, mas, sobretudo, pelo reconhecimento e autorreconhecimento de poder exercer a função de professora" (TORRES, 2012, p. 338). 
O reconhecimento e autorreconhecimento de ser docente foi também o contexto da pesquisa de Marina Reidel (2013). Analisou a Educação relacionada a temas como sexualidade, gênero, violência e preconceito, tentando descrever caminhos para uma Educação possível envolvendo todos esses elementos. No que se refere às docentes trans, saber qual é o lugar ocupado pela profissão docente nesse processo foi outro foco de sua dissertação, principalmente, quando suas identidades sexuais e de gênero são ressaltadas pelos sujeitos que integram a escola.

Como metodologia, foram entrevistadas sete professoras trans brasileiras cujo material empírico foi analisado, mormente, sob o olhar das teorias pós-críticas. Um dos aspectos conclusivos destacados refere-se à cobrança subjetiva de que a professora trans deve sempre alcançar os maiores índices de produtividade profissional para se firmar como pertencente e reconhecida naquele espaço.

Não basta serem as professoras, terão de ser as melhores e mais inteligentes, demonstrando conhecimento na área de atuação. Terão de garantir que os alunos aprenderam e, ainda mais, terão que ser o elo de ligação entre as direções que não sabem lidar com as situações do cotidiano da escola, em relação as queixas apresentadas por alunos vítimas de violência e homofobia no espaço escolar. (REIDEL, 2013, p. 102-103).

De acordo com o estudo de Franco (2014), essa condição de sobrevivência no ambiente escolar imposta a pessoas trans antecede a profissão docente. Ao contarem de suas vidas escolares, as professoras trans brasileiras - sujeitos de sua pesquisa -, ressaltaram como adolescentes e jovens estudantes LGBT são levados/as muitas vezes a desenvolverem rendimentos escolares acima da média. O intuito é de amenizarem os processos de exclusão e violência pelos quais são amiúde expostos/as no cotidiano escolar, expressados nos processos de intimidação, assédio, falta de acolhimento e desqualificações variadas (JUNQUEIRA, 2009b).

Franco (2014) investigou quais os caminhos percorridos e os obstáculos enfrentados por professoras trans brasileiras durante seu processo de escolarização e inserção na carreira docente. A pesquisa se sustentou na análise de fontes bibliográficas e documentais, entrevistas e questionários. Doze professoras trans das cinco regiões do país integraram o universo investigado.

Por serem interpretados/as como sujeitos que histórica e culturalmente devem ocupar as margens da sociedade, a presença da professora trans na escola desestabiliza os princípios hegemônicos da heteronormatividade. Isso ocorre, ainda que em alguns momentos, pelo fato de que a presença desses sujeitos possa representar uma conformação às normas de gênero no sentido de 'traírem' as diretrizes que reorganizam suas localizações de sujeito, fazendo de suas vivências trans uma dimensão invisibilizada pela estruturação de zonas de conforto da feminilidade. Em vários momentos, porém, essas zonas são abaladas. Como exemplo, quando interpretadas como uma variação da homossexualidade masculina ou quando questionadas pelos/as atores/as da escola sobre sua relação com a prostituição. De acordo com Franco (2014), mesmo com esses obstáculos, essas professoras desencadeavamm novos padrões de aprendizagem, convivência, produções diferenciadas de conhecimento, estabelecimentos de vínculos e, especialmente, perspectivas de que o respeito à diferença esteja cotidianamente em pauta. 


\section{4| CONSIDERAÇÕES FINAIS}

De acordo com nossa proposta de realizar um estado da arte sobre estudos que se dedicam à relação universo trans e suas nuances no campo educacional, descrevemos e contextualizamos acerca de vinte publicações em torno dessa temática; envolvendo textos publicados em anais de evento, artigos disponíveis em revistas eletrônicas, capítulos de livros, dissertações e teses. A segunda metade da primeira década do século XXI foi o demarcador de seu surgimento no contexto brasileiro, envolvendo tanto o universo discente quanto docente. Nossas buscas destacaram maior incidência desses estudos nas regiões Sul e Sudeste. As regiões Centro-Oeste e Nordeste foram identificadas como localidades menos exploradas nessa vertente investigativa; aspecto visualizado de forma ainda mais restrita na região Norte.

A construção de conhecimento científico sobre universo trans e Educação é uma preocupação também manifestada por docentes trans, das quais três foram por nós identificadas. Sales (2012) e Reidel (2013) concluíram mestrado em Educação e Andrade (2012) é a primeira professora trans do país a cursar e concluir Doutorado em Educação.

Esses trabalhos também elucidam uma carência de investigações sobre o universo da transexualidade masculina no contexto educacional, uma vez que somente no estudo de Santos (2010) encontramos esses sujeitos. Em razão de certa proximidade com o universo lésbico - o que poderia ser considerado um rito de passagem para alguns transexuais masculinos -, estariam esses sujeitos confinados ao campo da invisibilidade assim como o universo lésbico ao longo da história?

Outro campo de investigação aberto são os processos de construção docente de professores trans (masculinos) brasileiros. Registros recentes de sua visibilidade foram identificados em maio de 2011, com a realização do I Encontro Nacional da Rede Trans Educ Brasil (rede de professores trans no Brasil), realizado em Belo Horizonte-MG (TORRES, 2012; REIDEL, 2013). No entanto, João W. Nery (2011) destaca em sua autobiografia experiências como docente trans masculino anterior a esse período.

A emergência de maiores estudos sobre a inserção e permanência de pessoas trans no cotidiano escolar é uma das constatações mais relevantes evidenciadas neste estudo. Dentro das diversas dimensões que abrange as discussões sobre gênero e sexualidades dissidentes, travestis, transexuais e transgêneros permanecem historicamente como o segmento social mais exposto às mais variadas formas de vulnerabilidades e exclusão.

Como descrito na maioria dos estudos aqui apresentados, a escola é uma das principais instituições sociais que contribui para a reafirmação desses processos, portanto, seu interior torna-se um espaço propício para a construção de conhecimento no que se refere ao reconhecimento das diferenças e a criação de estratégias teóricas, práticas e políticas que melhor se aproximam dos princípios da inclusão. 


\section{Referências}

AMERICAN PSYCHIATRIC ASSOCIATION. Manual diagnóstico e estatístico de doenças mentais - DSM-IV. Porto Alegre: Artes Médicas; Loggos Treinamento e Informática, 1995. CD-ROM.

ANDRADE, L. N. de. Travestis na escola: assujeitamento e resistência à ordem normativa. 2012. 279 f. Tese (Doutorado em Educação) - Universidade Federal do Ceará, Fortaleza, 2012.

BENEDETTI, M. Toda feita: o corpo e o gênero das travestis. Rio de Janeiro: Garamond, 2005. 144 p.

BENTO, B. A. de M. O que é transexualidade. São Paulo: Brasiliense, 2008. 181 p. (Coleção Primeiros Passos).

BOHM, A. M. Os "monstros" e a escola: identidade e escolaridade de sujeitos travestis. 2009. 103 f. Dissertação (Mestrado em Educação) - Universidade Federal do Rio Grande do Sul, Porto Alegre, 2009.

BRASIL. Ministério da Educação e do Desporto. Secretaria de Educação Fundamental. Orientação sexual. In: Parâmetros curriculares nacionais: pluralidade cultural e orientação sexual. Rio de Janeiro: DP\&A, 2000. p. 107-161. v. 10.

BUTLER, J. P. Problemas de gênero: feminismo e subversão de identidade. Tradução Renato Aguiar. Rio de Janeiro: Civilização Brasileira, 2003. 236 p.

CAETANO, M. R. V. Gênero e sexualidade: um encontro político com as epistemologias de vida e os movimentos curriculares. 2011. 232 f. Tese (Doutorado em Educação)- Universidade Federal Fluminense, Niterói, 2011.

CAVALCANTI, M. P. de H. Gênero, educação e diversidade: sociabilidade das travestis nos ambientes educacionais na cidade de Maceió/AL. In: CONGRESSO LUSO AFRO BRASILEIRO DE CIÊNCIAS SOCIAIS, 11., 2011, Salvador. Anais... Salvador: UFBA, 2011. Disponível em: <http://www.xiconlab.eventos.dype.com. br/resources/anais/3/1308232879_ARQUIVO_ArtigoCONLAB.pdf>. Acesso em: 04 jul. 2012.

CÉSAR, M. R. de A. Um nome próprio: transexuais e travestis nas escolas brasileiras. In: REUNIÃO ANUAL DA ASSOCIAÇÃO NACIONAL DE PÓS-GRADUAÇÃO E PESQUISA EM EDUCAÇÃO, 32., 2009, Caxambu. Anais... Caxambu: ANPEd, 2009. 14 p.

CRUZ, E. F. Banheiros, travestis, relações de gênero e diferenças no cotidiano da escola. $R e-$ vista Psicologia Política, São Paulo, v. 11, n. 21, p. 73-90, jan./jun. 2011. Disponível em: <http:// pepsic.bvsalud.org/scielo.php?script=sci_arttext\&pid=S1519-549X2011000100007\&lng=pt\&nrm=i\&tlng=pt>. Acesso em: 10 mar. 2015.
DUQUE, T. Montagens e desmontagens: vergonha, estigma e desejo na construção das travestilidades na adolescência. 2009. 167 f. Dissertação (Mestrado em Sociologia)- Universidade Federal de São Carlos, São Carlos, 2009.

FERREIRA, Norma S. de A. As pesquisas denominadas "estado da arte". Educação \& sociedade, Campinas, ano 23, n. 79, p. 257-272, ago. 2002.

FRANCO, Neil. A diversidade entra na escola: histórias de professores e professoras que transitam pelas fronteiras da sexualidade e do gênero. 2009. 239 f. Dissertação (Mestrado em Educação) - Universidade Federal de Uberlândia, Uberlândia, 2009.

Professoras trans brasileiras: ressignificações de gênero e de sexualidades no contexto escolar. 2014. 266 f. Tese (Doutorado em Educação)- Universidade Federal de Uberlândia, Uberlândia, 2014.

HENRIQUES, R. et al. (Org.). Gênero e diversidade sexual na escola: reconhecer diferenças e superar preconceitos. Brasília, DF: MEC; Secad, 2007.

JUNCKES, I. J.; SILVA, J. M. Espaço escolar e diversidade sexual: um desafio às políticas educacionais no brasil. Revista de Didácticas Específicas, Madrid, n. 1, p. 148-166, dez. 2009. Disponível em: <http://www.didacticasespecificas.com/files/download/1/revistas/publicacion1.pdf\#page=14> Acesso em: 10 mar. 2015.

JUNQUEIRA, R. D. (Org.). Educação e homofobia: o reconhecimento da diversidade sexual para além do multiculturalismo liberal. In: Diversidade sexual na educação: problematizações sobre a homofobia nas escolas. Brasília, DF: MEC; Secad; UNESCO, 2009a. p. 367-444.

Homofobia nas escolas: um problema de todos. In:______. Diversidade sexual na educação: problematizações sobre a homofobia nas escolas. Brasília, DF: MEC; Secad; UNESCO, 2009b. p. 13-52.

Políticas de educação para a diversidade sexual: escola com lugar de direitos. In: LIONÇO, T.; DINIZ, D. (Org.). Homofobia \& educação: um desafio ao silêncio. Brasília, DF: Ed. UnB, 2009c. p. 161-193.

LOURO, G. L. Pedagogias da sexualidade. In: (Org.). O corpo educado: pedagogias da sexualidade. Belo Horizonte: Autêntica, 1999. p. 07-34.

MEYER, D. E.; PARAÍSO, M. A. Metodologias de pesquisas pós-críticas em educação ou sobre como fazemos nossas investigações. In: (Org.) Metodologias de pesquisas pós-críticas èm educação. Belo Horizonte: Mazza Edições, 2012. p. 15-21. 
TRAVESTIS, TRANSEXUAIS E TRANSGÊNEROS NA ESCOLA | Neil Franco e Graça A. Cicillini

NERY, J. W. Viagem solitária: memórias de um transexual trinta anos depois. São Paulo: Leya, 2011. 336 p.

NUNES, C.; SILVA, E. A educação sexual da criança: subsídios teóricos e propostas práticas para uma abordagem da sexualidade para além da transversalidade. Campinas: Autores Associados, 2000. 136 p.

PARAíSO, M. A. Metodologias de pesquisas pós-críticas em educação e currículos: trajetórias, pressupostos, procedimentos e estratégias analíticas. In: MEYER, D. E.; PARAíSO, M. A. (Org.). Metodologias de pesquisas pós-críticas em educação. Belo Horizonte: Mazza Edições, 2012. p. 23-45.

PERES, W. Cenas de exclusões anunciadas: travestis, transexuais, transgêneros e a escola brasileira. In: JUNQUEIRA, R. D. Diversidade sexual na educação: problematizações sobre a homofobia nas escolas. Brasília, DF: MEC; Secad; UNESCO, 2009. p. 235-264.

REIDEL, M. A pedagogia do salto alto: histórias de professoras transexuais e travestis na educação brasileira. 2013. 162 f. Dissertação (Mestrado em Educação)- Universidade Federal do Rio Grande do Sul, Porto Alegre, 2013.
SALES, A. Travestilidades e escola nas narrativas de alunas travestis. 2012. 115 f. Dissertação (Mestrado em Educação) - Universidade Federal de Mato Grosso, Rondonópolis, 2012.

SANTOS, D. B. C. Cartografias da transexualidade: a experiência escolar e outras tramas. 2010. 210 f. Dissertação (Mestrado em Educação) - Universidade Federal do Paraná, Curitiba, 2010.

SANTOS, S. P.; RODRIGUES, F. F. dos S. Cenas escolares vivenciadas por travestis: desafios à formação docente. In: ENCONTRO DE PESQUISA EM EDUCAÇÃO CENTRO OESTE, 12., 2014, Goiânia. Anais... Goiânia: Aned, 2014. CD-ROM.

SILVA, T. T. Documentos de identidade: uma introdução às teorias do currículo. 2. ed. Belo Horizonte: Autêntica, 2007. $154 \mathrm{p}$.

TORRES, M. A. A emergência de professoras travestis e transexuais na escola: heteronormatividade e direitos nas figurações sociais contemporâneas. 2012. $362 \mathrm{f}$. Tese (Doutorado em Psicologia)- Universidade Federal de Minas Gerais, Belo Horizonte, 2012. 